\title{
Using Employer Hiring Behavior to Test the Educational Signaling Hypothesis*
}

\author{
James W. Albrecht ${ }^{\dagger}$ \\ Jan C. van Ours
}

November 28, 2005

\begin{abstract}
This paper presents a test of the educational signaling hypothesis. If employers use education as a signal in the hiring process, they will rely more on education when less is otherwise known about applicants. We find that employers are more likely to lower educational standards when an informal, more informative recruitment channel is used. We thus reject the hypothesis that education is not used as a signal in the hiring process.
\end{abstract}

keywords: recruitment, signaling

JEL-codes: I20

*We thank two anonymous referees for their helpful comments.

${ }^{\dagger}$ Department of Economics, Georgetown University, Washington, DC 20057, USA, CESifo and IZA; albrecht@georgetown.edu.

${ }^{\ddagger}$ Department of Economics, Tilburg University, P.O. Box 90153, 5000 LE Tilburg, the Netherlands, CentER, CEPR and IZA; vanours@uvt.nl 


\section{Introduction}

This paper uses data about the hiring behavior of Dutch employers to test the educational signaling hypothesis. The idea of the test, based on Albrecht (1981), is that if education is a signal, then employers will rely more on education when less is otherwise known about an applicant. To apply this idea, we use information about the educational requirements attached to vacancies and about the education of the workers ultimately hired into those vacancies. That is, we compare ex ante educational requirements with ex post educational attainments. We also know the recruitment channels that employers used to fill their vacancies. We distinguish between informal and formal channels, and we assume that informal recruitment channels provide more information about potential new employees than formal recruitment channels do. Thus, we argue that if education is a signal, then employers will rely more on education if they use formal recruitment channels.

The contrapositive of the above statement is that if employer use of education in the hiring process is independent of recruitment channel, then education is not being used as a signal. This contrapositive is the basis for our null hypothesis of no signaling. When we take this hypothesis to the data, we find that a newly hired employee is more likely to have less than the originally required level of education if the employer hired that worker through an informal recruitment channel. This pattern obtains in a simple contingency table analysis, and it continues to hold when we use a competing risks framework to take into account the fact that vacancies are filled at different rates. In the competing risks analysis, we control for vacancy characteristics that might be associated with the propensity to relax educational requirements and/or with the

propensity to hire a worker who applied via an informal recruitment channel. This leads us to reject the null hypothesis of no signaling.

Our paper makes three contributions to the empirical literature on educational signaling. First, we test the educational signaling hypothesis using new data. Second, we develop a model that explicitly connects the test procedure in Albrecht (1981) to signaling theory. Third, we develop a new methodology for applying the basic idea in that paper. Specifically, the competing risks framework that we develop allows us to implement the idea in Albrecht (1981), even though we only have data on successful applicants. In contrast, the test procedure developed in the original paper required data on both accepted and rejected applicants. 


\section{Model}

Although our test procedure is intuitive, it is not immediately obvious how to connect it to the standard signaling model (Spence 1974). In the simplest version of that model, workers are either high productivity $(H)$ or low productivity $(L)$. Type $H$ workers have a low cost of education; the cost for type $L$ workers is high. In separating equilibrium, workers signal their types by their education choices - type $H$ workers choose a high level of education and are paid a high wage; type $L$ workers choose a low level of education and are paid a low wage. There is a positive return to education, even if education does not add to worker productivity. The interpretation of the returns to education implied by the simplest version of the signaling model is thus at odds with the interpretation implied by the standard human capital model (Becker 1993 [1964]).

In terms of our test procedure, the standard model is too extreme because in separating equilibrium, education is a perfect predictor of productivity. In this case, there is no value to further information, and the test procedure breaks down. No one would claim, however, that education is a perfect signal of productivity. In order to connect our test procedure to theory, we thus need a model in which education imperfectly signals productivity in separating equilibrium. To illustrate our main argument we distinguish between two extreme situations. In the first situation no information beyond schooling is available; in the second situation there is additional information that reveals the true productivity of the worker. We now sketch the basic characteristics of such a model, starting with the elements common to both extremes.

Suppose a worker's type is defined by her cost of acquiring education. To keep things simple, imagine there are two possible types, high-cost $\left(c_{H}\right)$ and low-cost $\left(c_{L}\right) .{ }^{1}$ The probability a worker is type $c_{H}$ is $p$. Type is private information, but $p$ is common knowledge. The worker is either high-productivity $\left(z_{H}\right)$ or low-productivity $\left(z_{L}\right)$ but does not know her productivity until she actually works. There is a negative correlation (not perfect) between cost and productivity, specifically, $P\left[z_{H} \mid c_{L}\right]=q_{L}$ and $P\left[z_{H} \mid c_{H}\right]=q_{H}$, where $q_{L}>q_{H}$. The worker is aware of this correlation, and these conditional probabilities are also known by the firm. Schooling does not affect the productivity of high-productivity workers, but if a low-productivity worker chooses the high level of schooling, then with probability $r$ she becomes a high-productivity worker. For some parameters values, all high-cost individuals choose the low level of schooling, and all low-cost individuals choose the high level of schooling, so there is separation of types in

\footnotetext{
${ }^{1}$ We could reinterpret low cost as high ability in schooling, e.g., less effort required to graduate, and similarly high cost could be reinterpreted as low ability.
} 
equilibrium.

In separating equilibrium, a fraction $1-q_{H}$ of high-cost individuals are low-productivity workers and a fraction $q_{H}$ are high-productivity workers. Since these workers do not acquire education in separating equilibrium, the ex ante and ex post fractions of this type that are highproductivity are the same. Among the low-cost workers, the ex post fraction of low-productivity workers is $(1-r)\left(1-q_{L}\right)$; a fraction $q_{L}+r\left(1-q_{L}\right)$ are high-productivity workers. Thus, once workers have made their education choices, the fraction of workers who are high-productivity is $p q_{H}+(1-p)\left(q_{L}+r\left(1-q_{L}\right)\right)$. Among these, a fraction $\frac{(1-p)\left(q_{L}+r\left(1-q_{L}\right)\right)}{p q_{H}+(1-p)\left(q_{L}+r\left(1-q_{L}\right)\right)}$ are highly educated; a fraction $\frac{p q_{H}}{p q_{H}+(1-p)\left(q_{L}+r\left(1-q_{L}\right)\right)}$ have the low education. Education is thus an imperfect indicator of productivity, but in separating equilibrium, there is a positive correlation between schooling and productivity. ${ }^{2}$

Now, consider the two extreme situations. In the first extreme, the employer only has information on schooling. Then, for some parameter configurations, it is optimal for workers with the low cost (high cost) to acquire the high (low) level of education, and it is optimal for the employer to hire only workers with a high level of schooling. As indicated, in this case the employer hires both high-productivity and low-productivity workers. The low-cost workers choose the high level of schooling in order to signal their type to employers. In the second extreme, the employer has additional information (call it $x$ ) that perfectly reveals the productivity of the workers. In that case, she hires only high-productivity workers. As indicated, employers then hire both high-educated and low-educated workers. In this case, there is no signaling. The reason that the low-cost workers choose the high level of schooling is only because education converts low-productivity workers to high-productivity workers with probability $r$.

In the first case, with $x$ completely uninformative, education is a signal and the firm relies exclusively on this signal in its hiring decisions. In the second case, with $x$ completely informative, workers make the same educational decisions as in the first scenario, even though education has no signaling value. However, since the more educated workers get the job with probability less than one, data on the firm's hiring process would indicate that the firm relies less heavily on education in this case. It is this interaction between the extent to which the firm relies on education in its hiring decision and the quality of other information about applicants that lies behind our test procedure.

In Albrecht (1981), data were available on all applicants, both the accepted and the rejected, for positions at a single firm. This made it possible to examine the differential effect of educa-

\footnotetext{
${ }^{2}$ That is, $(1-p)\left(q_{L}+r\left(1-q_{L}\right)\right)>p q_{H}$. If this inequality does not hold, then equilibrium cannot be separating.
} 
tion on the hiring probability for applicants who came via formal versus informal recruitment channels. As in our paper, it was assumed that the firm had relatively less information about applicants who came via formal recruitment channels. The dataset we analyze does not have information about rejected applicants. We do, however, have information about the stated educational requirements for vacancies, and we know whether the successful applicants for these vacancies had the required education or not. In terms of our model, we expect that the firm will be more likely to relax its educational requirement for applicants about whom it has more information. That is, we expect that educational requirements are more likely to be relaxed for applicants who are recruited through informal channels.

The general idea that, when signaling is important, employer behavior with respect to educational credentials should differ according to the quality of alternative information available has been used as a basis for other tests of the educational signaling hypothesis. These other tests have focused on wages, however, rather than on the hiring decision. Unfortunately, some of these tests have failed to recognize that signaling does not imply that the coefficient on education in a wage regression will change with the quality of alternative information that is available to employers. The reason is simply that employer estimates of productivity conditional on education, even when otherwise ill-informed, should be unbiased. Tests that distinguish between situations in which employers are well-informed versus ill-informed while avoiding this pitfall are presented in Riley (1979) and Altonji and Pierret (1998, 2001). Riley's (1979) informational distinction is between "screened" versus "unscreened" occupations, while Altonji and Pierret $(1998,2001)$ distinguish between new entrants to the labor force versus more experienced workers.

There are other approaches to testing the signaling hypothesis that are not based on informational distinctions of the sort that we are exploiting. For example, Lang and Kropp (1986) use the fact that compulsory school attendance laws differ across states in the U.S. Their idea is that if education is a signal, then an attendance law that forces low-ability workers to increase their educational attainment will lead high-ability workers to undertake further education in order to distinguish themselves. A related approach is taken by Bedard (2001). She argues that if university access is rationed, so that some high-ability high school graduates are unable to continue their education, then signaling would imply a decrease in the high-school dropout rate relative to what would be observed absent rationing. The reason is that low-ability individuals, who might otherwise drop out of high school, have more incentive to pool themselves with high-school graduates, the higher is the quality of high school graduates. Finally, instead of testing for the (non)existence of educational signaling, one could attempt to estimate the 
quantitative contribution of signaling to the returns to education. Fang (2005) does this using a structural econometric model, and concludes that signaling accounts for at most $1 / 3$ of the college wage premium.

\section{Data and Empirical Framework}

Employers use a variety of search methods to try to fill their vacancies, and workers use several search methods to try to find employment. In the Netherlands informal search methods, advertisements, and the employment office were the most commonly used methods (Lindeboom, Van Ours and Renes, 1993). Informal search channels are those that rely on word-of-mouth or some other "informal" method of contact. For workers, informal search methods include checking with friends or relatives. For employers, informal search methods include checking with friends, relatives or incumbent personnel. From our point of view the most important difference between formal and informal search methods is that informal search generates more information to employers.

The data we use are from a Dutch vacancy survey, which is described in detail in Van Ours and Ridder (1992). The vacancy survey was held in two stages. First, employers were asked about the characteristics of their vacancies. About four months later, employers were questioned about the vacancies that were filled in the meantime. Our sample contains information about 621 vacancies, of which 444 were filled between the dates of the two stages while 177 were still open at the second date. For every vacancy, we know the duration at the first date and either the date at which it was filled or the duration at the second date. From the first stage of the survey, we know the size of the firm and some characteristics of the vacancy, such as education and experience requirements, the occupation to which the vacancy pertains, and whether or not the vacancy was for a full-time job. ${ }^{3}$ For the vacancies that were filled, we know the educational level of the newly hired worker and we know which recruitment channel was used.

We assume that educational requirements have been adjusted downward if the educational level of a newly hired employee is lower than the educational level originally required for the vacancy filled by this employee. A first impression of the relationship between recruitment

\footnotetext{
${ }^{3}$ As measured in the first stage of the survey, only formal search channels were used for about $30 \%$ of the vacancies; for about $20 \%$ only informal channels were used; and for about $50 \%$ both formal and informal recruitment channels were used. In the first stage of the survey, some vacancies had been open only for a short while, so it is likely that employers used both formal and informal search channels for more than half of the vacancies.
} 
channel and adjustment of educational requirements can be derived from the contingency table presented as Table 1. The educational standard was adjusted downward for $24 \%$ of the 126 filled vacancies for which an informal recruitment channel was used. Such an adjustment was made for only $13 \%$ of the 318 filled vacancies for which a formal recruitment channel was used. The null hypothesis of independence between recruitment channel and adjustment of educational requirements is rejected at the $5 \%$ level. The $\chi^{2}$ from the contingency table is equal to 7.53 (critical $\chi^{2}=3.84$ ). At first glance, it thus appears that education is indeed a signal that is less relevant when other information is available.

However, the relationship between recruitment channel and adjustment of educational standards may also be caused by differences in observed or unobserved characteristics of firms or vacancies. If, for example, large firms are more likely to use formal recruitment channels and are more strict about their hiring standards, then there is no causal relationship between recruitment channel and the adjustment of educational standards. The relationship between recruitment channel and adjustment of educational standards may also be affected by how long the vacancy has remained unfilled. To correct for the effects of observed and unobserved characteristics and for the effects of elapsed duration, we estimated a competing risks duration model with four risks: adjustment and informal recruitment, adjustment and formal recruitment, non-adjustment and informal recruitment and non-adjustment and formal recruitment.

The hazard rates are specified as

$$
\theta_{j, k}(t ; x, v)=\exp \left(x \prime \beta_{j}+\lambda_{j} d_{1} v_{j, k}\right),
$$

where $x$ is a vector of explanatory variables, $d_{1}$ is a dummy variable which is one in the time interval after 1 month, $v$ is an unobserved component, $\beta$ is a vector of coefficients, $\lambda$ is a coefficient for duration dependence and $j$ is an indicator of type of exit (risk), $j=1, . ., 4$ ( $1=$ Required education downward adjusted, informal recruitment channel; $2=$ Required education downward adjusted, formal recruitment channel; $3=$ Required education non-adjusted, informal recruitment channel; $4=$ Required education non-adjusted, formal recruitment channel), and $k$ is and indicator for unobserved heterogeneity.

We assume the heterogeneity components follow a discrete distribution with two points of support:

$$
h\left(v_{j, 1}\right)=p \text { and } h\left(v_{j, 2}\right)=1-p .
$$

The points of support and the probability $p$ are parameters to be estimated. We reparametrize $p$ as $\exp (\gamma) /[1+\exp (\gamma)]$. 
The firms that provided information about their vacancies were approached twice. The first time all vacancies were open, with incomplete vacancy durations $t_{1}$. After about four months the firms were approached for a second interview. From this second interview we know whether the vacancy was filled in these four months and, if so, when it was filled. Furthermore, we know which recruitment channel the successful applicant used and we know whether or not this appliant's level of education was equal to or lower than the required education. The date at which the vacancy was filled is given by $t_{2}$ (so the total duration is $t_{1}+t_{2}$ ). In constructing the likelihood, we use the conditional distribution of the residual vacancy duration $t_{2}$ given the incomplete duration $t_{1}$ and the type of exit $j$. The likelihood contribution if a vacancy is filled at a known date $t_{2}$ through exit $j$ is

$$
\frac{\sum_{k=1}^{2} p_{k} \theta_{j, k}\left(t_{1}+t_{2}\right) \exp \left[-\int_{0}^{t_{1}+t_{2}} \sum_{j=1}^{4} \theta_{j, k}(s) d s\right]}{\sum_{k=1}^{2} p_{k} \exp \left[-\int_{0}^{t_{1}} \sum_{j=1}^{4} \theta_{j, k}(s) d s\right]},
$$

and if the vacancy is open at $t_{2}$, when the type of exit is not determined yet, the likelihood contribution is

$$
\frac{\sum_{k=1}^{2} p_{k} \exp \left[-\int_{0}^{t_{1}+t_{2}} \sum_{j=1}^{4} \theta_{j, k}(s) d s\right]}{\sum_{k=1}^{2} p_{k} \exp \left[-\int_{0}^{t_{1}} \sum_{j=1}^{4} \theta_{j, k}(s) d s\right]}
$$

As explanatory variables we use the variables described in the notes to Table 2.

\section{Parameter estimates}

The parameters of the model are estimated by maximum likelihood. The estimation results are shown in Table 2a. Many of the estimates do not differ from zero at conventional levels of significance. None of the estimated coefficients on firm size, full-time, and production workers is significantly different from zero; that is, these variables appear to affect neither the speed at which vacancies are filled nor the path by which these vacancies are filled. Only one of the estimated coefficients on experience is significantly less than zero. The interpretation of this coefficient estimate is that vacancies for which experience is required are less likely to be filled through a formal recruitment channel by a worker who has a lower level of education than required. All of the estimated coefficients on required education differ significantly from zero. Furthermore, it appears that the probability that educational requirements are adjusted is higher if the level of required education is higher. We found some evidence of unobserved heterogeneity but no evidence for duration dependence. The estimate for $\gamma$ indicates that conditional on the observed characteristics there are two types of vacancies that differ in the rates 
at which they are filled. The first group, which comprises about $20 \%$ of the vacancies, is more likely to be filled via an informal recruitment channel and to adjust educational requirements downward. For the second group, since $v_{2}-v_{1}=-\infty$ for exit 1 , the transition rate for this type of exit is zero. The second group of vacancies is more likely to be filled without adjusting educational requirements and via a formal recruitment channel than is the first group.

If we restrict our model to a specification without unobserved heterogeneity and duration dependence, the log likelihood value drops by 4.6 points (Table 2b). From this we conclude that we can ignore both unobserved heterogeneity and duration dependence. ${ }^{4} \mathrm{~A}$ comparison of Tables $2 \mathrm{a}$ and $2 \mathrm{~b}$ shows that the estimates of the coefficients on the firm and vacancy characteristics are hardly affected. Whereas the lack of duration dependence has no particular meaning other than that apparently not all applicants arrive at the start of the vacancy, the lack of unobserved heterogeneity is more interesting. Apparently the relationship between recruitment channel and adjustment of educational requirements is not affected by unobserved variables. This suggests that selectivity - in the sense of different worker types using different search channels - is not an important issue in the hiring process.

Table $2 \mathrm{c}$ shows the parameter estimates if we drop the four variables with mostly insignificant coefficients. The log likelihood value drops by 7.5 points. Since the Likelihood Ratio statistic is 15.0 and the critical $\chi^{2}$-value for 16 degrees of freedom is 26.3 we cannot reject the hypothesis that these variables do not affect the process by which vacancies are filled.

The most interesting question is whether there is a relationship between adjusting educational requirements and the recruitment channel through which the vacancy is filled. We investigated this by imposing independence, using the specification without unobserved heterogeneity or duration dependence and restricting ourselves to the variables with significant coefficients. That is, our null hypothesis is:

$$
\begin{aligned}
v_{4,1}-v_{2,1} & =v_{3,1}-v_{1,1} \\
\beta_{4}-\beta_{2} & =\beta_{3}-\beta_{1}
\end{aligned}
$$

The restriction that $v_{4,1}-v_{2,1}=v_{3,1}-v_{1,1}$ indicates that, controlling for the variables that had significant coefficients in our initial specification, a firm is as likely to stick to its educational requirement when its vacancy is filled through a formal channel as when the vacancy is filled

\footnotetext{
${ }^{4}$ Note that a formal Likelihood Ratio test is problematic since one of the parameters $(\gamma)$ is not identified under the null hypothesis. The difference in the values of the log likelihoods is rather small considering there are 4 duration dependence parameters and, apart from $\gamma$, there are 4 unobserved heterogeneity parameters $\left(v_{j, 2}\right)$; the Likelihood Ratio test statistic is 9.2 , while the critical $\chi^{2}$-value for 8 degrees of freedom is 15.5 .
} 
through an informal channel. That is, under the interpretation suggested by our model, the firm's use of education in the hiring process does not depend on whether its chosen applicant comes via an uninformative or an informative recruitment channel. Similarly, the restriction that $\beta_{4}-\beta_{2}=\beta_{3}-\beta_{1}$ indicates that the differential effects of the included covariates do not depend on whether the successful applicant came via a formal or an informal recruitment channel. Thus, for example, educational requirements are more likely to be adjusted downward. the higher is the stated requirement, but the effect of the level of the stated requirement on the probability of adjustment is independent of recruitment channel.

As shown in Table 2d, the restrictions imposed by equations (5) and (6) cause the log likelihood to drop 5.3 points. The Likelihood Ratio statistic comparing the two results is equal to 10.6, which is significantly larger than the critical $\chi^{2}$-value of 7.8 for 3 degrees of freedom. Therefore, even conditional on the characteristics of the vacancy, the adjustment of educational standards is not independent of the recruitment channel.

\section{Conclusion}

We conclude that when employers hire new employees, they are more likely to deviate from their stated educational requirements if there is information from other sources, in particular, when an informal recruitment channel is used. This is consistent with the view that education is used as a signal. Of course, it is possible that a lack of independence between adjustment of educational requirements and recruitment channel could arise for other reasons. One possibility is that there might be legal reasons why firms could be more committed to their stated educational requirements when using formal recruitment channels. A second possibility is that workers who can do the job in question but who lack the specified educational credentials may be more willing to apply through informal than through formal channels. That is, one could imagine a potential selection explanation for our results. Finally, as suggested above, there may be vacancy characteristics that are correlated both with the propensity to relax educational requirements and to hire through informal channels. We have tried to control for these alternatives as best as we could, and we take comfort from the facts that (i) both informal and formal channels were used to recruit applicants for at least half of the vacancies and (ii) we found no evidence that unobserved heterogeneity affected the hiring process. Even admitting the possibility of alternative explanations, we therefore feel that our empirical results are most naturally interpreted as support for the educational signaling hypothesis. 


\section{References}

Albrecht J.W. (1981) A Procedure for Testing the Signalling Hypothesis, Journal of Public Economics, 15, 123-132.

Altonji, J.G. and C.R. Pierret (1998) Employer Learning and the Signaling Value of Education, in Ohashi, I. and T. Tachibanaki, eds. Internal Labor Markets, Incentives and Employment, McMillan Press, 159-95.

Altonji, J.G. and C.R. Pierret (2001) Employer Learning and Statistical Discrimination, Quarterly Journal of Economics, 116, 313-350.

Becker, G.(1993) [1964] Human Capital, Columbia University Press, 3rd edition.

Bedard, K. (2001) Human Capital versus Signaling Models: University Access and High School Dropouts, Journal of Political Economy, 109, 749-775.

Fang, H. (2005) Disentangling the College Wage Premium: Estimating a Model with Endogenous Education Choices, International Economic Review, forthcoming.

Lang, K. and D. Kropp (1986) Human Capital Versus Sorting: The Effects of Compulsory Attendance Laws, Quarterly Journal of Economics, 101, 609-624.

Lindeboom, M., J.C. van Ours and G. Renes (1993) Matching Employers and Workers: an Empirical Analysis on the Effectiveness of Search, Oxford Economic Papers, 46, 45-67.

Ours, J.C. van and G. Ridder (1992) Vacancies and Recruitment of New Employees, Journal of Labor Economics, 10, 138-155.

Riley, J.G. (1979) Testing the Educational Screening Hypothesis, Journal of Political Economy, $87, \mathrm{~S} 227-\mathrm{S} 252$.

Spence, A. M. (1974) Market Signalling: Informational Transfer in Hiring and Related Screening Processes, Harvard University Press. 
Table 1 - Filled vacancies by recruitment channel and adjustment of educational requirements

a. Numbers

\begin{tabular}{|c|c|c|c|}
\hline \multirow{2}{*}{ Educational requirements } & \multicolumn{3}{|c|}{ Recruitment channel } \\
\cline { 2 - 4 } & Informal & Formal & Total \\
\hline Adjusted downward & 30 & 42 & 72 \\
\hline No downward adjustment & 96 & 276 & 372 \\
\hline Total & 126 & 318 & 444 \\
\hline
\end{tabular}

b. Column percentages

\begin{tabular}{|c|c|c|c|}
\hline \multirow{2}{*}{ Educational requirements } & \multicolumn{3}{|c|}{ Recruitment channel } \\
\cline { 2 - 4 } & Informal & Formal & Total \\
\hline Adjusted downward & 23.8 & 13.2 & 16.2 \\
\hline No downward adjustment & 76.2 & 86.8 & 83.8 \\
\hline Total & 100.0 & 100.0 & 100.0 \\
\hline
\end{tabular}


Table 2 - Parameter estimates ${ }^{a)}$

\section{a. Full model}

\begin{tabular}{|c|c|c|c|c|}
\hline Required education & \multicolumn{2}{|c|}{ Adjusted downward } & \multicolumn{2}{c|}{ No downward adjustment } \\
\hline Recruitment channel & Informal & Formal & Informal & Formal \\
\hline & $(1)$ & $(2)$ & $(3)$ & $(4)$ \\
\hline Type of job $^{b}$ & \multicolumn{5}{|c|}{} \\
\hline Firm size & $-0.20(1.0)$ & $-0.12(0.8)$ & $-0.04(0.4)$ & $0.06(0.9)$ \\
\hline Experience & $0.95(1.5)$ & $-0.08(0.1)$ & $-0.28(1.0)$ & $-0.49(2.4)^{* *}$ \\
\hline Full-time & $-0.10(0.1)$ & $0.14(0.1)$ & $-0.31(0.7)$ & $-0.35(1.2)$ \\
\hline Required education & $0.86(1.8)^{*}$ & $0.73(1.7)^{*}$ & $-0.72(4.4)^{* *}$ & $-0.38(3.2)^{* *}$ \\
\hline Production workers & $\left.-{ }^{c}\right)$ & $-0.08(0.1)$ & $-0.25(0.4)$ & $0.48(1.3)$ \\
\hline Commercial workers & $0.91(1.7)^{*}$ & $0.72(2.0)^{* *}$ & $0.42(1.8)^{*}$ & $0.38(2.3)^{* *}$ \\
\hline Duration effects & \multicolumn{5}{|c|}{} \\
\hline $1+$ months & $0.27(0.3)$ & $-0.13(0.2)$ & $-0.06(0.1)$ & $0.40(1.3)$ \\
\hline Heterogeneity & \multicolumn{5}{|c|}{$-1.34(1.9)^{*}$} \\
\hline$v_{1}$ & $-5.78(2.5)^{* *}$ & $-5.67(3.2)^{* *}$ & $-0.58(0.7)$ & $-2.38(2.6)^{* *}$ \\
\hline$v_{2}-v_{1}$ & $-\infty$ & $-1.12(0.7)$ & $0.35(0.5)$ & $1.70(2.7)^{* *}$ \\
\hline$\gamma$ & \multicolumn{5}{|c|}{1436.2} \\
\hline \hline -Log likelihood & \multicolumn{5}{|c|}{} \\
\hline
\end{tabular}

b. No duration dependence or unobserved heterogeneity

\begin{tabular}{|c|c|c|c|c|}
\hline & $(1)$ & $(2)$ & $(3)$ & $(4)$ \\
\hline Firm size & $-0.07(0.4)$ & $-0.07(0.6)$ & $-0.04(0.4)$ & $0.04(0.9)$ \\
\hline Experience & $0.17(0.3)$ & $-0.33(0.8)$ & $-0.22(0.9)$ & $-0.32(2.1)^{* *}$ \\
\hline Full-time & $-0.27(0.3)$ & $-0.03(0.0)$ & $-0.25(0.6)$ & $-0.18(0.8)$ \\
\hline Required education & $0.24(0.7)$ & $0.72(2.6)^{* *}$ & $-0.60(4.2)^{* *}$ & $-0.17(1.9)^{*}$ \\
\hline Production workers & $-^{b)}$ & $-0.23(0.2)$ & $-0.24(0.4)$ & $0.54(2.1)^{* *}$ \\
\hline Commercial workers & $0.75(1.9)^{*}$ & $0.66(2.1)^{* *}$ & $0.42(1.9)^{*}$ & $0.50(3.7)^{* *}$ \\
\hline$v_{1}$ & $-4.61(3.4)^{* *}$ & $-5.68(4.1)^{* *}$ & $-0.57(0.9)$ & $-1.28(3.4)^{* *}$ \\
\hline \hline -Log likelihood & \multicolumn{5}{|c|}{1440.8} \\
\hline
\end{tabular}


c. Restricted number of variables

\begin{tabular}{|c|c|c|c|c|}
\hline & $(1)$ & $(2)$ & $(3)$ & $(4)$ \\
\hline Required education & $0.20(0.7)$ & $0.65(2.6)^{* *}$ & $-0.66(4.9)^{* *}$ & $-0.22(2.6)^{*}$ \\
\hline Commercial workers & $0.75(2.0)^{* *}$ & $0.70(2.2)^{* *}$ & $0.48(2.2)^{* *}$ & $0.47(3.7)^{* *}$ \\
\hline$v_{1}$ & $-4.97(4.7)^{* *}$ & $-6.11(6.8)^{* *}$ & $-1.03(2.6)^{* *}$ & $-1.28(4.8)^{* *}$ \\
\hline \hline -Log likelihood & \multicolumn{4}{|c|}{1448.3} \\
\hline
\end{tabular}

d. Independence imposed

\begin{tabular}{|c|c|c|c|}
\hline & $(1)$ & $(2)$ & $(3)$ \\
\hline Required education & $0.21(1.0)$ & $0.54(2.8)^{* *}$ & $-0.57(4.6)^{* *}$ \\
\hline Commercial workers & $0.74(2.7)^{* *}$ & $0.71(2.8)^{* *}$ & $0.50(2.5)^{* *}$ \\
\hline$v_{1}$ & $-5.44(7.4)^{* *}$ & $-5.53(7.9)^{* *}$ & $-1.18(3.1)^{* *}$ \\
\hline \hline- Log likelihood & \multicolumn{3}{|c|}{1453.6} \\
\hline
\end{tabular}

a) Absolute t-statistics in parentheses.

b) Firm size = natural logarithm of the number of employees at the firm; experience $=$ dummy variable equal to 1 if work experience is required; full-time $=$ dummy variable equal to 1 if vacancy is advertised for a full-time job; required education = level of required education (ranging from 1 to 4); production workers = dummy variable for production workers; commercial workers $=$ dummy variable for service, clerical or commercial workers.

${ }^{c}$ ) Because of lack of observations we could not estimate this coefficient.

${ }^{*}\left({ }^{* *}\right)=$ significantly different from zero at $10 \%(5 \%)$ level. 